Relations industrielles

Industrial Relations

\title{
Syndicalisme, consommation et société de consommation, par Bernard Solasse, Étude no 3, Équipe spécialisée en relations de travail, Ottawa, Bureau du Conseil privé, 1968, 47 pages.
}

\section{Jacques Lafrenière}

Volume 26, numéro 1, 1971

URI : https://id.erudit.org/iderudit/028197ar

DOI : https://doi.org/10.7202/028197ar

Aller au sommaire du numéro

Éditeur(s)

Département des relations industrielles de l'Université Laval

ISSN

0034-379X (imprimé)

1703-8138 (numérique)

Découvrir la revue

Citer ce compte rendu

Lafrenière, J. (1971). Compte rendu de [Syndicalisme, consommation et société de consommation, par Bernard Solasse, Étude no 3, Équipe spécialisée en relations de travail, Ottawa, Bureau du Conseil privé, 1968, 47 pages.] Relations industrielles / Industrial Relations, 26(1), 241-241.

https://doi.org/10.7202/028197ar

Tous droits réservés @ Département des relations industrielles de l'Université Laval, 1971
Ce document est protégé par la loi sur le droit d'auteur. L'utilisation des services d’Érudit (y compris la reproduction) est assujettie à sa politique d'utilisation que vous pouvez consulter en ligne.

https://apropos.erudit.org/fr/usagers/politique-dutilisation/ 


\section{RECENSIONS}

Syndicalisme, consommation et société de consommation, par Bernard Solasse, Etude no 3, Equipe spécialisée en relations de travail, Ottawa, Bureau du Conseil privé, 1968, 47 pages.

Bernard Solasse qui fut un certain temps conseiller auprès de la Confédération des syndicats nationaux, était bien placé pour aborder le sujet de cette étude. L'auteur le précise dans son introduction: c'est une étude de cas qui porte sur l'action et les prises de position de la CSN dans le domaine de la consommation.

Cette étude est antérieure aux décisions des gouvernements de protéger les consommateurs dans les limites de certaines lois. Bernard Solasse a donc dû puiser là où les renseignements étaient disponibles. Il s'est largement inspiré de l'aide apportée par le Service du budget familial de la CSN.

L'action de cette centrale syndicale dans le domaine de la consommation part du résultat de trois facteurs, selon M. Solasse :

1-l'endettement croissant des syndiqués et des salariés en général ;

2-l'amélioration du pouvoir d'achat des syndiqués et d'une façon plus générale, des salariés-consommateurs ;

3-le dynamisme agissant et mobilisateur d'une forte personnalité, André Laurin, dont le travail que ce dernier accomplit à la CSN depuis 1962 a fortement inspiré l'auteur.

Les objectifs poursuivis par la CSN, seule ou en collaboration avec d'autres organismes, peuvent se regrouper, selon $M$. Solasse, autour de ces quatre thèmes majeurs :

1 - l'aide qui est essentiellement l'assistance juridique aux syndiqués et aux salariés endettés;

2-l'information et l'éducation du syndiqué et du consommateur;

3-l'amélioration du pouvoir d'achat du consommateur; 4-l'action politique visant à la fois l'opinion publique et les différents niveaux de gouvernements.

M. Solasse constate qu'une étude de cas, «en surcroît descriptive », se prête mal aux généralisations théoriques.

Cette étude a été préparée au moment où le service que dirige M. Laurin obtenait ses plus grands succès. Il serait à souhaiter que l'étude soit complétée et pour certaines questions, approfondie, pour savoir, par exemple, s'il est vrai et dans quelle mesure, M. Laurin a réussi à susciter et affermir la prise de conscience du syndiqué-consommateur.

Il est indéniable que les divers organismes non syndicaux qui ont fait l'éducation et l'information du consommateur ont éveillé l'attention du citoyen qui était aux prises avec des difficultés économiques très grandes. Ces organismes sont les Associations coopératives d'économie familiale (ACEF), les Caisses d'économie, les magasins Coop.

En somme, M. Solasse a tracé le programme d'une plus vaste étude qui pourrait être non seulement intéressante pour les chercheurs, mais essentielle dans une société qui ne peut plus se définir autrement que par ces deux mots déjà familiers : société de consommation.

Jacques LAFRENIERE

Adaptation and Innovation in Wage Payment Systems in Canada, by Jack Chernik, Study no 5, Task Force on Labour Relations, Ottawa, Privy council office, 1970, $130 \mathrm{pp}$.

Firms can be expected to adapt their wage payment system to the changing economic environment in which they function. In the present period in Canadian economic development the nature of technical advances, trade union attitudes and government economic and industrial relations policies provide the most important influences determining this environment. Professor Jack Cher- 